\title{
Infection status of Mycoplasma hyopneumoniae in experimental pigs at a commercial farm
}

\author{
Huyen T. N. Bui ${ }^{*}$, Hien T. Le, \& Toan T. Nguyen
}

Faculty of Animal Science and Veterinary Medicine, Nong Lam University, Ho Chi Minh City, Vietnam

\author{
ARTICLE INFO \\ Research Paper \\ Received: March 05, 2020 \\ Revised: May 11, 2020 \\ Accepted: June 09, 2020

\section{Keywords} \\ Antibodies \\ ELISA \\ Infection ratio \\ Mycoplasma hyopneumoniae (MH) \\ PCR

\section{* Corresponding author} \\ Bui Thi Ngoc Huyen \\ Email: huyen.btngoc@gmail.com
}

\section{ABSTRACT}

The objective of this study was to investigate the profiles of Mycoplasma hyopneumoniae (MH) infection at different ages of pig in a sow - finishing herd using serological and molecular methods. A total of 30 study piglets were born from non-vaccinated sows with $\mathrm{MH}$. They were injected one-dose of inactivated $\mathrm{MH}$ vaccine at the $10^{\text {th }}$ week. $\mathrm{MH}$ infection status was evaluated by using ELISA to detect $\mathrm{MH}$ antibodies from blood samples, and PCR to detect MH DNA in nasal swabs or oral fluid samples every other weeks from newborn to slaughter time. The results of this study showed that PCR positive proportions were low at $1^{\text {st }}-2^{\text {nd }}$ week (7-13\%), then increased significantly during $5^{\text {th }}-7^{\text {th }}$ week $(73-79 \%)$, and reduced at $8^{\text {th }}$ week $(33 \%)$; finally became negative after $13^{\text {th }}$ week of age. This pattern corresponds to the one of antibody level. In particular, the level of maternal antibodies against $\mathrm{MH}$ was very high due to maternal immunity, then decreased gradually to negative at 7-8 weeks of age, and finally increased gradually from 13 weeks of age to all positive at 25 weeks of age. In conclusion, the result showed that in this herd, $\mathrm{MH}$ might invade pigs by the time of 5-7 weeks of age after maternal immunity disappears, and humoral response can overcome the infection at week 13. This should be noted to have appropriate strategies to control $\mathrm{MH}$ at the farm.

Cited as: Bui, H. T. N., Le, H. T., \& Nguyen, T. T. (2020). Infection status of Mycoplasma hyopneumoniae in experimental pigs at a commercial farm. The Journal of Agriculture and Development $19(3), 22-27$.

\section{Introduction}

Mycoplasma hyopneumoniae (MH) is a principal aetiological agent of porcine enzootic pneumonia (EP), a respiratory disease that mainly affects growing and finishing pigs (Maes et al., 1996). MH infection causes damage to the lung lesions, and modulates immune response of the host. MH primary infection often becomes more serious when getting co-infections by other bacteria and viruses such as Pasteurella multocida, Streptococcus suis, Actinobacillus pleuropneumoniae (APP), Porcine Respiratory and Reproductive Syndrome Virus (PRRSV), and Porcine Circovirus type 2 (PCV2), etc. leading to a complica- tion called Porcine Respiratory Disease Complex (PRDC) (Thacker et al., 2000). Once infected, pigs become stunted, low growth rate, poor feed conversion ratio (FCR), as a result of high culling rate in the herd, massive cost of treatment, and getting more susceptible to secondary pathogens (Thacker \& Minion, 2012). It is estimated that approximately $80 \%$ of pig production had been affected with the disease and every one infected pig cost approximately 4-7 USD (Haden et al., 2012).

In order to evaluate the effectiveness of the vaccination plan, it is essential to get a better understanding the situation of $\mathrm{MH}$ infection throughout stages of production in farm. The objective 
of this study was to investigate the dynamics of $\mathrm{MH}$ infection at different ages in a pig herd by using ELISA and PCR to detect both antibodies and the bacterium DNA. The result of this study also helped to estimate the infected time and risk period under field conditions.

\section{Materials and Methods}

\subsection{Experimental design}

The study was conducted from February 2019 to October 2019 in a medium - scale pig farm with a scale of 1000 grow-finisher pigs and 200 sows, a type of open-housing system, in Xuan Loc district, Dong Nai Province.

A total of thirty piglets from five $3^{\text {rd }}-5^{\text {th }}$ parity sows that these sows had been checked to be free of PRRSV, CSFV and MH based on PCR tests (one week before farrowing) on individual oral fluid samples and determined level of antibody against $\mathrm{MH}$ basing on ELISA test (one hour after farrowing) was enrolled in the study. From each sow, 3 male and 3 female newborn piglets with the same size and the same body conditions were selected, and individually marked by ear tags from number 1 to 30, raised stable during the whole period of the study. According to vaccination program of farm, all these piglets were injected one-dose of Bayovac ${ }^{\circledR}$ MycoGuard ${ }^{\circledR}-1$ vaccine at the $10^{\text {th }}$ day of age. The piglets were weaned at 24 days-old and mixed together in only one pen (basic floor pen) until they were transported to slaughterhouse.

The MH infection status of experimental pigs was determined via testing of both blood samples and nasal swab/ oral fluid samples at different ages. Sampling timeline was designed according to life-stage of study pigs, i.e. the first 60 days of age (week 1-8); nursery phase (week 9-12) and finishing phase (week $13-25$ ). In particular, individual blood samples were taken from study pigs based on week-age, i.e. week 1, 2, 4, 5, 7, 8, 13, 19 and 25 weeks, respectively. In addition to blood samples, individual nasal swabs were collected for the first 8 weeks of age, however, pooled oral fluid samples were collected for whole studied group at the later stages (week 13, 19 and 25).

Each sampling time, only $50 \%$ of studied pigs would be sampled and $50 \%$ remain pigs would be sampled at the next time to avoid piglets having been bled for 2 consecutive weeks. In details, at the $1^{\text {st }}$ week, 3 piglets per litter were selected alternately male or female to collect samples for every 2 weeks, and at the following week the other half would be sampled for every 2 weeks. It means a total of 15 piglets were assigned to take samples per week throughout the timeline except for the week of weaning.

\subsection{ELISA and PCR procedures}

From the nasal swabs and oral fluids, DNA was extracted to run a standard PCR to detect a fragment of $16 \mathrm{~S}$ rRNA gene of $\mathrm{MH}$. The assay was previously described and performed by using primers according to Abhijit et al. (2012) with the specific primers (sequence with 5' - 3' direction) for DNA amplification (F: ACTAGATAGGAAATGCTCTAG and R: ATACTACTCAGGCGGATCATTTAAC) to have a product of 430bp in length. Blood samples were stored in cool condition for less than 24 hours, after that serum was aspirated from the tube and frozen in refrigerator $-20^{\circ} \mathrm{C}$ until analysis. These serum samples were analyzed for the presence of antibodies against $\mathrm{MH}$ with an indirect ELISA (IDEXX M. hyo. Ab test kit, USA). The output of ELISA was read with a $650 \mathrm{~nm}$ filter to calculate the $\mathrm{S} / \mathrm{P}$ value of each sample. The result is defined as positive when $\mathrm{S} / \mathrm{P}$ ratios were $>0.4$, $\mathrm{S} / \mathrm{P}$ ratios of 0.3 to 0.4 were classified as suspect and $\mathrm{S} / \mathrm{P}$ ratios $<0.3$ were classified as negative. $\mathrm{MH}$ antibody titer was evaluated from S/P using the formula recommended by the kit producer: Titer $=\operatorname{Antilog}_{10}\left(1.09 * \log _{10}(\mathrm{~S} / \mathrm{P})+3.36\right)$. These laboratory procedures were performed at the diagnostic center of Veterinary Hospital of Nong Lam University, Ho Chi Minh City, Vietnam.

\subsection{Statistical analysis}

Data was managed and performed simple analysis using Microsoft Excel 2013 (Microsoft Corp., Redmond, WA). Proportions of sample number being positive were calculated, and means of titer with standard error were calculated for each sampling time. Multilevel regression was used to model the pattern of $\mathrm{MH}$ titer in which dependent variable was titer, independent variables included week age, quadratic week age, cubic week age, sex (male/female), day-0 weight, maternal MH (positive/negative), and litter identification was random variable. Backward elimination ap- 
proach was used to build the final model with the statistical significance level $(\mathrm{P})$ of 0.05 . The final parameter model results are applied to a simulation data for graphing dynamics of $\mathrm{MH}$ infection of pig in the herd. These steps were performed with STATA 14 software (StataCorp., 2015. Stata Statistical Software: Release 14. College Station, TX: StataCorp LP).

\section{Results and Discussion}

\subsection{Detection of MH by PCR}

The presence of MH detected by PCR in nasal swabs (week 1 - week 8) and oral fluids (week 13week 25) are shown in Figure 1.The $\mathrm{MH}$ infection proportion at the first week was $7 \%(1 / 15)$, then it gradually rises to $13 \%$ and $20 \%$ at week 2 and week 4, respectively (Figure 1). A significant increase of $\mathrm{MH}$ infection is observed and reached $79 \%$ at week 7 . However, at 8 weeks of age, the $\mathrm{MH}$ infection proportion dropped markedly to $33 \%$.

After 8 weeks of age, the number of samples required to detect $\mathrm{MH}$ DNA of study pigs is high, which result in costly diagnosis. To overcome some of these limitations, instead of taking individual nasal swab samples, we obtained pooled oral fluid samples for the group of study pigs to perform PCR. For the pooled oral fluid samples, all of them were negative for $\mathrm{MH}$ at week 13 , week 19 and week 25 . It was generally interpreted that the individual could also be considered all study pigs were negative with $\mathrm{MH}$ or $\mathrm{MH}$ infection rate was in very low level, so that the result was negative at all.

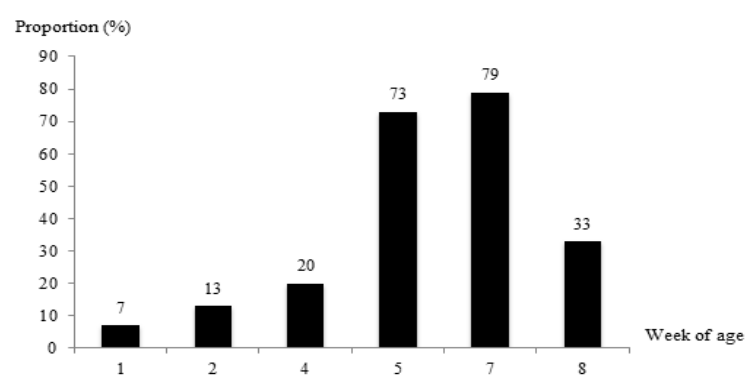

Figure 1. The MH infection proportion defined by PCR in pigs by the week of age.

MH infection at week 1 was the lowest could be explained by negative $\mathrm{MH}$ shedding sows selected and the effects of the passive transfer of maternal $\mathrm{MH}$ antibodies and specific cellular immunity to piglets via colostrum. The maternal immunity are known critical to prevent or reduce the impact of infectious diseases in the neonate for a few days to several weeks after birth. In the studied farm, MH vaccination is applied for piglets not in sow. That means enzootic pneumonia might be endemic in a sow herd particularly in continuous production systems (Sheldrake et al., 1990; Bandrick et al., 2008), and the maternal immunity are ready in sow in such level to transfer to piglets. In fact, all sows were negative in PCR result for $\mathrm{MH}$ but $3 / 5$ sows were positive with antibody by ELISA (data not shown). And MH might be from the environment to accidentally infect to a pig.

From week 2, maternal MH antibodies have not been enough to help them fight the disease; however, these suckling piglets are in nursing phase so that rarely exposed to the external environment, the proportion was increasing slowly. The weaning age of 21 days was the time that the maternally immunity eventually wanes (Meyns et al., 2004). These piglets separated from their sows experienced marked physiological, environmental, mixing and social challenges (stressors) that could predispose them to MH infection. Therefore, the period between week 4 and week 7 , it was the potential to increase the susceptibility of piglets to get infection by impact of $\mathrm{MH}$ in the environment and from the other infectious penmates.

The infection proportion began to diminish and especially reach zero with $\mathrm{MH}$ at week 13, 19 and 25 by pooled oral fluid samples. It was generally supposed that the results of these pooled samples could be as follows: if the results are negative, the individual could also be considered all study pigs were negative with $\mathrm{MH}$ or $\mathrm{MH}$ infection rate was in very low level inconsiderably, so that the result was negative at all. It is known that the high-risk period of $\mathrm{MH}$ infections occurrence under field production conditions is the phase after transfer of animals to the finishing facilities (10 weeks of age) (Léon et al., 2001). Moreover, during this period, the farm increased the use of antimicrobials, minerals and vitamins via feed and water to control $\mathrm{MH}$ and maintain pig health. Thus, these antimicrobials for the treatment and control of $\mathrm{MH}$ infections could be helpful in affected pigs. Based on above considerations, the negative results of pooled oral fluid samples at every sampling time demonstrated for efficiency of antibiotics on reducing the positive rate with 
$\mathrm{MH}$ infection by PCR. These findings is similar to the previous study that all pen-based oral fluid samples for $\mathrm{MH}$ in finishing phase were negative (Sibila et al., 2007). Piglets were vaccinated with inactivated vaccine which might slow induce immunity, but at these points of time, high level of antibody from field infection and vaccine could boost to the level of eliminating the bacteria. Finally, these results indicated the presence of $\mathrm{MH}$ in the respiratory tract, which could be related to the presence of antibodies in the blood of study pigs.

\subsection{Detection of MH antibody}

After performing ELISA tests for serum samples, the $\mathrm{MH}$ antibody positive proportion and means of titers by week age are illustrated in Figure 2. At the first week of age, the antibody positive proportion with $\mathrm{MH}$ was highest $(53 \%)$, equivalent to the highest antibody titer of 1532.47. After that, the rate of positive serum for MH began to decrease from the second week (proportion of $40 \%$, titer of 904.04 ) to week 8 , only $0 \%$, equivalent to the antibody concentration of 204.59. Then, the antibody positive proportion as well as mean of titer increased significantly and reached $100 \%$ (1321.59) at week 25 . These results coincide with those obtained in field studies using ELISA by Morrison et al. (1985) who noted that antibodies to $M$. hyopneumoniae were detected again at 90 to 150 days of age, and Sheldrake et al. (1990) reported that most pigs seroconverted between 86 and 144 days of age.

According to Figure 1 and Figure 2, the MH infection status was illustrated compatibly when positive ratios in PCR and ELISA result had contrary directions. In the present study, high prevalence of $\mathrm{MH}$ infection occurred around the time of post-weaning period until beginning of finishing period. The critical moment for the exposure to $M$. hyopneumoniae was around 9-10 weeks of age and most of them have very low concentrations of antibodies against the agent.

\subsection{Modeling of antibody titer against $\mathrm{MH}$}

Antibody titer values from the studied piglets by age were modeled to understand the pattern of its change and any other related factors such as gender, body weight, maternal antibody, etc. The result from modeling found that week-age has a cubic relationship with antibody titer. Maternal antibody (MAB) in this model is a binary variable in which the sow transferred $\mathrm{MH}$ antibody to piglets or not. The reason is that each piglet can receive different level of MAB. The other concerned variables were not significant in the modeling construction. The final model is described in Table 1 and the simulation of this model can be seen in Figure 3. The positive result was confirmed when $\mathrm{S} / \mathrm{P}$ ratios were $>0.4$, so the cut-off value was calculated as 843 according to the kit formula with $\mathrm{S} / \mathrm{P}=0.4$ to classify boundary of $\mathrm{MH}$ titer with or without MAB.

According to modeling illustration, we found that the average age at which piglets lost protection lies well between $2^{\text {nd }}$ week and $4^{\text {th }}$ week. The titer of pigs having MAB did not decline as rapidly as those of without-MAB pigs. Additionally, we observed that the lowest level of antibodies was in the period from 8 th week to 10 th week of age; and protection afforded by MAB had higher level than piglets lacking of MAB. Afterwards, from week 16 to 20 , the diagram indicated that both groups had a seroconversion that the antibody level reached to detectable values and continued to increase. However, we assessed that MAB group increased titer earlier than that of the without MAB pigs.

\subsection{General discussion}

Thacker et al. (2000) suggested that both local mucosal antibodies and systemic cell-mediated immunity responses are important for protection. Therefore, by using serum to detect IgG antibodies to MH by ELISA, this study cannot evaluate the mucosal antibody because $\mathrm{MH}$ is a mucosal pathogen which mainly adheres to the cilia of the epithelial cells on the respiratory tract, the production of IgA antibody blocking $\mathrm{MH}$ attachment to the mucosal surface is believed to play a key role in protection (Zhang et al., 1995). It is generally that IgA predominates in the mucosal secretions, whereas IgG predominates in serum. However, there was no correlation between antibody titer or IgG concentrations in serum and level of protection against $\mathrm{MH}$ infection (Djordjevic et al., 1997). Thus, it is difficult to link the antibody to the presence of $\mathrm{MH}$ on the respiratory track, and this presence cannot refer to infection. However, at least, the antibody level in serum can imply the time of infection in piglet. That means it is valuable comparing to $\mathrm{PCR}$ which might more refer to the high risk time. 


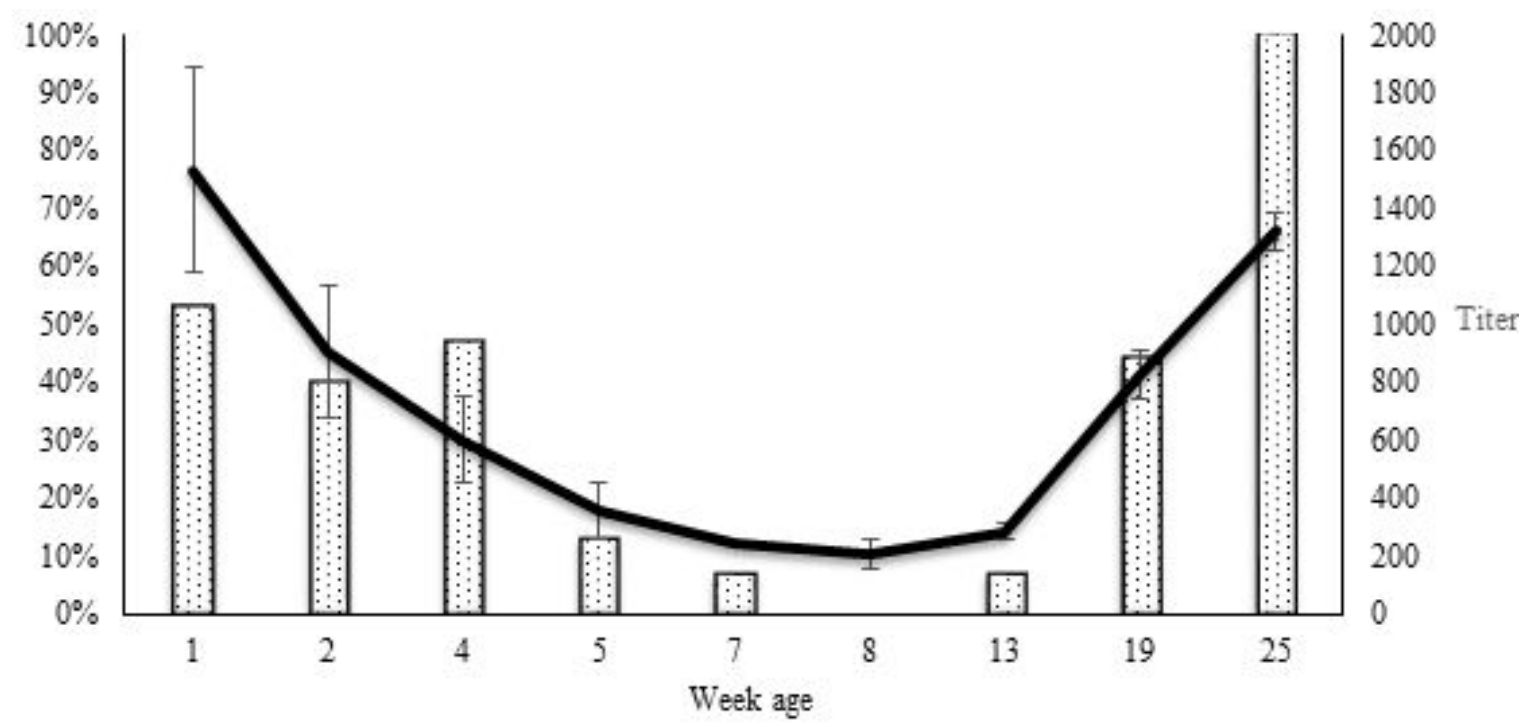

Figure 2. Antibody positive percentage (bars) and antibody level against $\mathrm{MH} \pm \mathrm{SE}$ (line) in pigs by week of age.

Table 1. Modeling of piglet antibody titer values by variables

\begin{tabular}{lcccc}
\hline Variables & Coefficient & 95\% Confidence & Interval & $\mathrm{P}$ value \\
\hline (Week age) & -391.825 & -499.498 & -284.152 & $<0.001$ \\
(Week age $^{2}$ & 28.678 & 18.921 & 38.435 & $<0.001$ \\
(Week age) $^{3}$ & -0.549 & -0.794 & -0.305 & $<0.001$ \\
MAB & 383.192 & 213.323 & 553.062 & $<0.001$ \\
Constant & 1510.820 & 1193.526 & 1828.114 & $<0.001$ \\
\hline
\end{tabular}

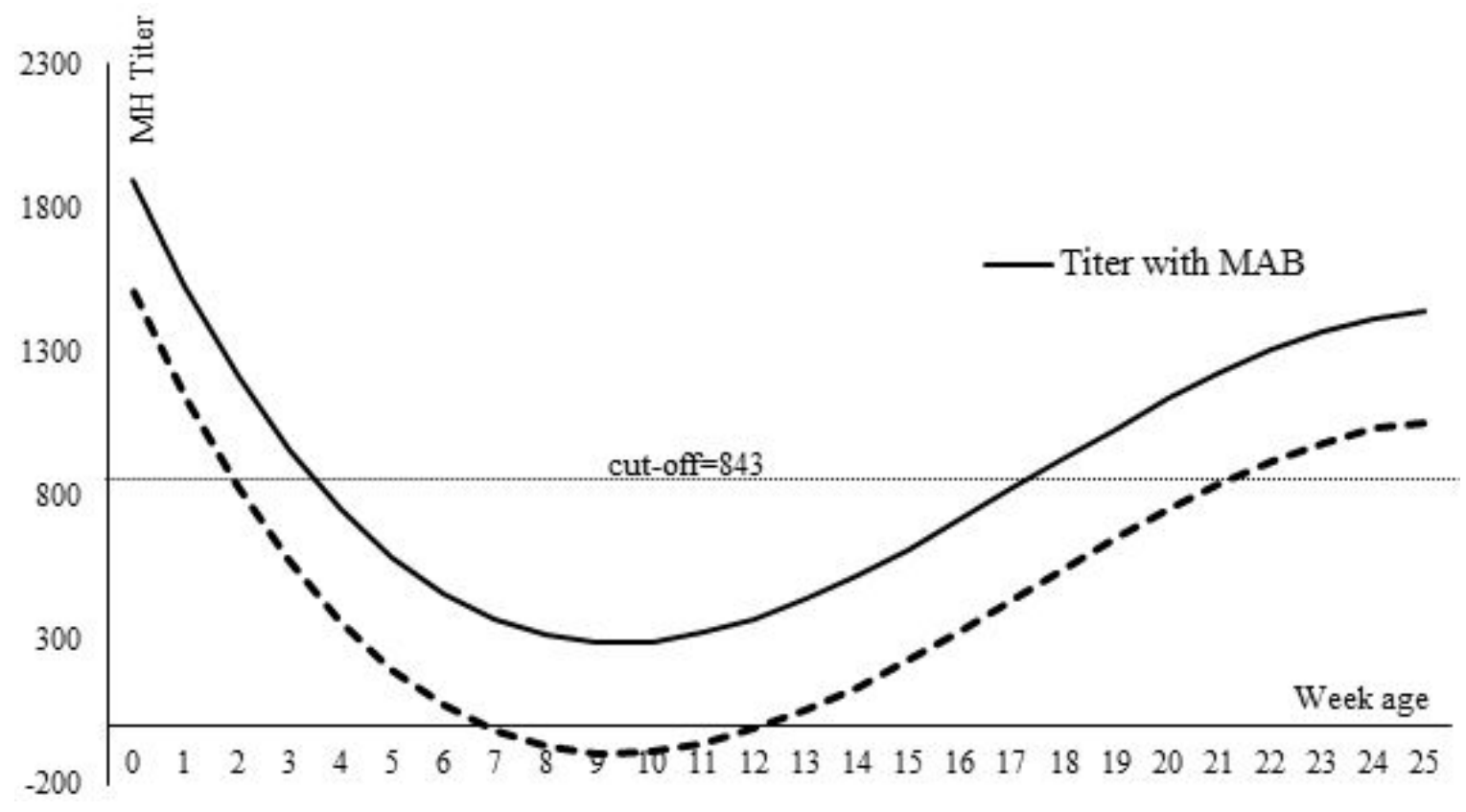

Figure 3. Modeling pig MH antibody titer values by variables (week age, with or without maternal immunity). 
Resistance to the disease after recovering appears to be dependent on a balance between the immune status of the animals and the pathogen load. In the study, those pigs received antibiotics like other herds in farm via feed and water additives. Additionally, under field conditions, antimicrobial treatment may be effective against bacteria respiratory pathogens specifically $\mathrm{MH}$, and it can be implemented to reach a low infectious pressure in the farm at that moment (Thacker \& Minion, 2012). This given medication modifies the pig' microbiota and alteration of epithelial mucosal bacteria influences development on the study pigs' respiratory immune system (Arsenakis et al., 2017). Thus, besides vaccination, several treatment strategies should be considered as the sole to mitigate expression of disease and reduce prevalence within herd.

\section{Conclusions}

High prevalence of $\mathrm{MH}$ in the farm and the infection occurred from the time of 2-3 weeks after weaning until beginning of finishing period, weeks 9-10.

\section{Acknowledgements}

The study was sponsored by Scientific Research Fund of Nong Lam University, HCMC, Vietnam. We would like to express our gratitude to the farm owner for their facility and other volunteer student for sample collection.

\section{References}

Abhijit, K. B., Lee, H. Y., Jeong, H. W., Truong, L. Q., Joo, H. G., \& Hahn, T. W. (2012). An improved multiplex PCR for diagnosis and differentiation of $M y$ coplasma hyopneumoniae and Mycoplasma hyorhinis. Korean Journal of Veterinary Research 52, 39-43.

Arsenakis, I., Michiels, A., del Pozo Sacristán, R., Boyen, F., Haesebrouck, F., \& Maes, D. (2017). Mycoplasma hyopneumoniae vaccination at or shortly before weaning under field conditions: a randomised efficacy trial. Veterinary Record 181(1), 19.

Bandrick, M., Pieters, M., Pijoan, C., \& Molitor, T. W. (2008). Passive transfer of maternal Mycoplasma hyopneumoniae-specific cellular immunity to piglets. Clinical and vaccine immunology 15, 540-543.

Djordjevic, S. P., Eamens, G. J., Romalis, L. F., Nicholls, P. J., Taylor, V., \& Chin, J. (1997). Serum and mucosal antibody responses and protection in pigs vaccinated against Mycoplasma hyopneumoniae with vaccines containing a denatured membrane antigen pool and adjuvant. Australian Veterinary Journal 75, 504511.

Haden, D. C., Painter, T., Fangman, T., \& Holtkamp, D. (2012). Assessing production parameters and economic impact of swine influenza, PRRS and $M y$ coplasma hyopneumoniae on finishing pigs in a large production system. Proceedings of American Association of Swine Veterinarians Annual (75-76). Denver, Colorado, America.

Léon, E. A., Madec, F., Taylor, N. M., \& Kobisch, M. (2001). Seroepidemiology of Mycoplasma hyopneumoniae in pigs from farrow-to-finish farms. Veterinary Microbiology 78, 331-341.

Maes, D., Verdonck, M., Deluyker, H., \& de Kruif, A. (1996). Enzootic pneumonia in pigs. Veterinary Quarterly 18, 104-109.

Meyns T., Maes D., Dewulf J., Vicca, J., Haesebrouck F., \& de K. A. (2004). Quantification of the spread of Mycoplasma hyopneumoniae in nursery pigs using transmission experiments. Preventative Vetererinary Medicine 66, 265-275.

Morrison, R. B., Hilley, H. D., \& Leman, A. D. (1985). Comparison of methods for assessing the prevalence and extent of pneumonia in market weight swine. Canadian Veterinary Journal 26, 381-384.

Sheldrake, R. F., Gardner, L. A., Saunders, M. M., \& Romalis, L. F. (1990). Serum antibody response to $M y$ coplasma hyopneumoniae measured by enzyme-linked immunosorbent assay after experimental and natural infection of pigs. Australian Veterinary Journal 67, 3942 .

Sibila, M., Nofrarias, M., Lopez-Soria, S., Segales, J., Valero, O., Espinal, A., \& Calsamiglia, M. (2007). Chronological study of Mycoplasma hyopneumoniae infection, seroconversion and associated lung lesions in vaccinated and non-vaccinated pigs. Veterinary $M i$ crobiology 122, 97-107.

Thacker, E. L., Thacker, B. J., Kuhn, M., Hawkins, P. A., \& Waters, W. R. (2000). Evaluation of local and systemic immune responses induced by intramuscular injection of a Mycoplasma hyopneumoniae bacterin to pigs. American Journal of Veterinary Research 61, 1384-1389.

Thacker E., \& Minion, F. (2012). Mycoplasmosis. In Zimmerman, J. J., Karriker, L. A., Ramirez, A., Schwartz, K. J., \& Stevenson, W. G. (Eds.). Diseases of Swine (10 ${ }^{\text {th }}$ ed., 779-798). New Jersey, USA: WileyBlackwell.

Zhang, Q., Young, T. F., \& Ross, R. F. (1995). Identification and characterisation of a Mycoplasma hyopneumoniae adhesin. lnfection lmmunology 63, 1013-1019. 